\title{
Update on ambulatory anesthesia
}

\author{
Paul F. White PhD MD FAnZCA
}

A

MBULATORY surgery accounts for over $60 \%$ of all elective operative procedures performed in the United States. With the recent growth in major laparoscopic and office-based surgery, this percentage may increase to $70 \%$ in the future. When surgery is performed outside the conventional hospital environment, it can offer a number of advantages for patients, healthcare providers, third-party payers, and even hospitals. ${ }^{1}$ Patients benefit from day-surgery because it minimizes costs, decreases separation from their home and family environment, reduces surgery waiting times, decreases their likelihood of contracting hospitalacquired infections, and appears to reduce postoperative complications. Compared to traditional hospital admissions, there is less pre- and postoperative lab testing and also a reduced demand for postoperative pain medication following ambulatory surgery. Unlike inpatient surgery, ambulatory surgery does not depend upon the availability of a hospital bed and may permit the patient greater flexibility in selecting the time of their elective operation. Furthermore, there is greater efficiency in the utilization of the operating and recovery rooms in the ambulatory setting, contributing to a decrease in the overall patient charges compared to similar hospital-based care.

\section{Comparison of general, spinal and local anesthesia}

The optimal anesthetic technique in the ambulatory setting would provide for excellent operating conditions, a rapid recovery, no postoperative side effects, and a high degree of patient satisfaction. In addition to increasing the quality and decreasing the costs of the anesthetic services, the ideal anesthetic technique would also improve operating room (OR) efficiency and provide for an early discharge home without side effects. Local anesthesia with iv sedation [so-called monitored anesthesia care (MAC)], spinal anesthesia, and general anesthesia are all commonly used anesthetic techniques for ambulatory surgery. However, opinions differ as to the "best" anesthetic technique for these surgical procedures. ${ }^{2-15}$ Rather than simply generalizing as to the best anesthetic technique for ambulatory surgery, it is necessary to individually analyze each surgical procedure. For example, in an editorial in Anesthesia \& Analgesia, ${ }^{16}$ Kehlet and White discussed the optimal anesthetic technique for inguinal hernia repair.

In the current cost-conscious environment, it is important to also examine the impact of anesthetic techniques on OR turnover times, as well as the recovery process after ambulatory surgery because prolonged recovery times and reduced efficiency and productivity contribute to increased cost of surgical care (Tables I and II). ${ }^{10}$ In addition, patient satisfaction with their perioperative experience and quality of recovery is improved when the anesthetic technique chosen for the procedure is associated with a low incidence of postoperative side effects [e.g., pain, dizziness, headaches, postoperative nausea and vomiting $(\mathrm{PONV})] \cdot{ }^{10,11}$ For example, routine use of prophylactic antiemetic drugs during general anesthesia has been found to increase patient satisfaction in "at risk" surgical populations. ${ }^{17}$ Furthermore, the use of local anesthetic infiltration and peripheral nerve blocks decreases postoperative pain after ambulatory surgery procedures irrespective of the anesthetic technique. . $^{48,19}$

The time required to achieve a state of home-readiness ("fitness" for discharge home) is influenced by a wide variety of surgical and anesthetic factors. ${ }^{20,21}$ However the major contributors to delays in discharge after ambulatory surgery are nausea, vomiting, dizziness, pain and prolonged sympathetic and/or motor blockade. Although the incidence of PONV can be decreased by the use of prophylactic antiemetic drugs, ${ }^{17}$ it remains a common side effect after general anesthesia and prolongs discharge after ambulatory surgery. ${ }^{10,11}$ The primary factors delaying discharge after spinal anesthesia are recovery from the residual motor blockade and sympatholytic effects of the subarachnoid block, contributing to delayed ambulation and inability to void. These side effects can be minimized by the use of so-called mini-dose lidocaine fentanyl spinal anesthetic techniques. ${ }^{13,15}$ Other common concerns with spinal

From the Department of Anesthesiology \& Pain Management, University of Texas Southwestern Medical Center, Dallas, Texas, USA. Address correspondence to: Dr. Paul F. White, Department of Anesthesiology \& Pain Management, University of Texas Southwestern Medical Center, 5323 Harry Hines Boulevard, Dallas, Texas, USA. Phone: 214-648-6424; Fax: 214-648-2920;

E-mail: paul.white@utsouthwestern.edu 
TABLE I Patient demographic characteristics, surgical, anesthetic, and recovery times for the three anesthetic techniques used for anorectal in the ambulatory setting ${ }^{10}$

\begin{tabular}{llll}
\hline & Local anesthesia with sedation & Spinal anesthesia & General anesthesia \\
\hline Number $(n)$ & 31 & 31 & 31 \\
Age (yr) & $40 \pm 9$ & $43 \pm 10$ & $41 \pm 9$ \\
Weight $(\mathrm{kg})$ & $83 \pm 18$ & $82 \pm 16$ & $82 \pm 22$ \\
Height $(\mathrm{cm})$ & $171 \pm 11$ & $169 \pm 8$ & $172 \pm 10$ \\
Sex (M/F) (n) & $22 / 9$ & $21 / 10$ & $24 / 7$ \\
ASA physical status (I /II/III) (n) & $10 / 18 / 3$ & $10 / 16 / 5$ & $11 / 15 / 5$ \\
Duration of surgery (min) & $26 \pm 14$ & $26 \pm 13$ & $26 \pm 15$ \\
Duration of anesthesia (min) & $40 \pm 15$ & $72 \pm 17^{*}$ & $75 \pm 19^{*}$ \\
Phase 1 PACU stay (min) & 0 & $52 \pm 18^{*}$ & $44 \pm 27^{*}$ \\
Phase 2 DSU stay (min) & $71 \pm 17$ & $135 \pm 113^{*}$ & $120 \pm 52^{*}$ \\
Time to oral intake (min) & $12 \pm 5$ & $99 \pm 18^{*}$ & $60 \pm 29^{*}$ \\
Initial Aldrete score in recovery (n) & $10 \pm 0$ & $19 \pm 7^{*}$ & $8.3 \pm 0.7^{*} \dagger$ \\
Time to Aldrete score of 10 (min) & 0 & $30 \pm 19^{*} \dagger$ \\
Time to home-readiness (min) & $76 \pm 17$ & $266 \pm 112^{*}$ & $171 \pm 58^{*}$ \\
Duration of hospital stay (min) & $116 \pm 21$ & $247 \pm 65^{*}$ \\
\hline
\end{tabular}

Values are mean $\pm \mathrm{SD} .{ }^{*} P<0.05$ vs local anesthesia with sedation. $\dagger P<0.05$ vs spinal anesthesia. PACU = postanesthesia care unit; DSU = day surgery unit.

TABLE II Incremental costs associated with the three anesthetic techniques for outpatient anorectal surgery ${ }^{10}$

\begin{tabular}{|c|c|c|c|}
\hline & Local anesthesia with sedation & Spinal anesthesia & General anesthesia \\
\hline \multicolumn{4}{|l|}{ Intraoperative costs (USD) } \\
\hline Drugs & $23.16 \pm 9.29$ & $3.92 \pm 1.35^{*}$ & $48.22 \pm 7.72^{*} \dagger$ \\
\hline Supplies & $4.23 \pm 0.27$ & $13.29 \pm 0.35^{*}$ & $9.1 \pm 0.24^{*} \dagger$ \\
\hline Total OR drugs + supplies & $27.39 \pm 9.39$ & $17.21 \pm 1.55^{*}$ & $57.32 \pm 7.89^{*} \dagger$ \\
\hline OR labor costs & $36.34 \pm 14.04$ & $66.30 \pm 15.17^{*}$ & $68.45 \pm 14.04^{*}$ \\
\hline Total intraoperative costs & $63.73 \pm 20.69$ & $83.50 \pm 15.17^{*}$ & $125.78 \pm 20.69 * \dagger$ \\
\hline \multicolumn{4}{|l|}{ Recovery costs (USD) } \\
\hline Drugs & $0.10 \pm 0.20$ & $0.63 \pm 2.92$ & $1.80 \pm 4.94$ \\
\hline Supplies & 0 & $0.15 \pm 0.47^{*}$ & $0.80 \pm 0.82 * \dagger$ \\
\hline \multicolumn{4}{|l|}{ Nursing labour costs } \\
\hline Phase 1 & 0 & $9.46 \pm 3.22^{*}$ & $8.04 \pm 4.94 *$ \\
\hline Phase 2 & $5.20 \pm 1.23$ & $9.94 \pm 3.22 *$ & $8.79 \pm 3.78^{*}$ \\
\hline Total & $5.20 \pm 1.23$ & $19.40 \pm 8.87^{*}$ & $16.83 \pm 6.14^{*}$ \\
\hline Total recovery costs & $5.29 \pm 1.39$ & $20.37 \pm 9.15^{*}$ & $18.63 \pm 9.96^{*}$ \\
\hline \multicolumn{4}{|l|}{ Perioperative costs (USD) } \\
\hline Total drug costs & $23.26 \pm 9.25$ & $4.55 \pm 3.68^{*}$ & $50.03 \pm 8.50^{*} \dagger$ \\
\hline Total supplies & $4.23 \pm 0.27$ & $9.72 \pm 0.46^{*}$ & $13.44 \pm 0.47^{*} \dagger$ \\
\hline Total labour costs & $41.54 \pm 13.88$ & $85.67 \pm 17.83$ * & $85.29 \pm 18.79^{*}$ \\
\hline Total perioperative costs & $69.02 \pm 20.39$ & $103.68 \pm 18.13^{*}$ & $145.02 \pm 25.31 * \dagger$ \\
\hline
\end{tabular}

Values are mean \pm SD in United States dollars (USD). ${ }^{*} P<0.05$ vs local anesthesia with sedation. $\dagger P<0.05$ vs spinal anesthesia.

anesthesia include back pain, post-dural puncture headache and transient radicular irritation with lidocaine. ${ }^{22,23}$ Although MAC is associated with the lowest incidence of postoperative side effects, ${ }^{10,11}$ the possibility of transient nerve palsy is a concern when peripheral nerve block techniques are used. ${ }^{25,26}$

The cost savings with the use of newer general anesthetic techniques are lost if institutional practices mandate minimum lengths of stay in the Phase 1 unit [postanesthesia care unit (PACU)] and do not permit fast-tracking of patients who emerge rapidly from anesthetic directly to the Phase 2 [day-surgery ("stepdown")] unit. Claims of reduced total costs with earlier discharge are commonly based on the assumption that there is a linear relationship between the costs of a service and the time spent providing it. However, since personnel costs are semi-fixed rather than variable, an additional 15 to 30 min stay in the PACU may not be associated with increased costs to the institution unless the facility is working at or near its capacity. ${ }^{27}$ In that sit- 
uation, a longer stay is potentially associated with a "bottleneck" in the flow of patients through the OR suites and recovery areas, requiring overtime payments to the nurses and/or the hiring of additional perioperative personnel. There appears to be a much closer relationship between lower costs and bypassing of the PACU ("fast-tracking"), as the major factor in recovery care costs relates to the peak number of patients admitted to the PACU unit at any time. ${ }^{27}$ Fast-tracking can lead to the use of fewer nurses and a mix of less highly trained, lower wage nursing aides and fully-qualified recovery room nurses, and reduces "overtime" personnel costs for busy ambulatory surgery units. Shorter anesthesia times, the ability to bypass the PACU (Phase 1 ), and a decreased length of stay in the day-surgery (Phase 2) unit will reduce total institutional costs. ${ }^{28}$ Studies have demonstrated that "fast-tracking" ambulatory surgery patients decrease the times to actual discharge (Tables I and III). ${ }^{29,30}$

The combination of low costs and high patient satisfaction suggests that the highest quality (cost/outcome) anesthetic may be achievable with a MAC technique assuming that the surgical procedure is amendable to this anesthetic approach (e.g., superficial surgical and endoscopic procedures). Cost estimates of different anesthetic regimens for ambulatory surgery are available (Table II). ${ }^{10}$ Unfortunately, many pharmacoeconomic studies have limited cost considerations to only the acquisition costs of the drugs and supplies rather than the total (direct + indirect) expenses associated with a given anesthetic technique. The total cost should include both the acquisition costs of drugs and the labour required for managing side effects (e.g., PONV, pain, drowsiness, bladder dysfunction). Since personnel costs constitute a major proportion of expenses in the OR and recovery areas, anesthetic techniques which require more time in the various phases of the perioperative process will not surprisingly be more expensive (Table II). ${ }^{10,11}$

The availability of improved sedation and analgesia techniques to complement local anesthetic infiltration has increased the popularity of performing surgery utilizing MAC techniques. ${ }^{31}$ The high patient satisfaction with local anesthesia/sedation is also related to effective control of postoperative pain and the absence of side effects associated with the other commonly used general and spinal anesthetic techniques. The success of MAC techniques is dependent not only on the anesthesiologist, but also upon the skills of the surgeon in providing effective infiltration analgesia and gentle handling of the tissues during the intraoperative period. Local anesthesia without any monitoring or iv adjuvants (so-called "unmonitored" local
TABLE III Effect of fast-tracking on time to discharge and patient satisfaction after outpatient gynecologic laparoscopic surgery ${ }^{29,30}$

\begin{tabular}{lll}
\hline & $\begin{array}{l}\text { Conventional } \\
\text { recovery }\end{array}$ & $\begin{array}{l}\text { Fast-track } \\
\text { recovery }\end{array}$ \\
\hline Age (yr) & $30 \pm 6$ & $28 \pm 5$ \\
Weight $(\mathrm{kg})$ & $69 \pm 22$ & $74 \pm 14$ \\
Surgery time (min) & $36 \pm 11$ & $37 \pm 12$ \\
Home ready (min) & $151 \pm 50$ & $112 \pm 46^{*}$ \\
Discharged home (min) & $206 \pm 46$ & $159 \pm 63^{*}$ \\
Patient satisfaction $(0-100)$ & $93 \pm 5$ & $94 \pm 4$ \\
\hline
\end{tabular}

*Significantly different from "conventional" pathway, $P<0.05$.

anesthesia), has been successfully used in situations where local anesthesia is able to provide excellent analgesia and patients do not object to being awake and aware of events in the OR. ${ }^{32}$ The importance of good surgical skills is critically important because inadequate intraoperative control of pain can lead to prolonged surgery times and patient dissatisfaction with their surgical experience. In a prospective, randomized comparison of local infiltration with spinal and general anesthesia, ${ }^{33}$ surgeons in Sweden suggested the technical difficulties and patient pain were "more intense" during surgery under local anesthesia. This finding is consistent with an earlier report by Fairclough et al. ${ }^{34}$ However, with these surgical provisions, it is widely accepted that superficial surgical procedures can be performed as safely and effectively under local anesthesia as under any other form of anesthesia. In fact, the researchers in Sweden concluded that "for most patients, local anesthesia can be recommended as the standard procedure for outpatient knee arthroscopy". ${ }^{33}$

While most studies have suggested that local anesthesia (e.g., local infiltration and/or peripheral nerve blocks) are not only well-accepted by patients and surgeons for superficial outpatient procedures (e.g., breast surgery, knee arthroscopy, anorectal surgery, and inguinal herniorrhaphy) but is also more cost-effective than either spinal or general anesthesia, ${ }^{10,11,35}$ some studies have suggested that spinal anesthesia is more cost-effective than general anesthesia. ${ }^{5,7}$ These and other studies ${ }^{13,15}$ have suggested that the use of smaller dosages of lidocaine (15-30 mg) or bupivacaine (3-6 $\mathrm{mg}$ ) combined with a potent opioid (e.g., fentanyl, 12.5-25 $\mu \mathrm{g}$, or sufentanil, 5-10 $\mu \mathrm{g}$ ) contributes to a faster recovery of both motor and bladder function than conventional doses of the local anesthetic alone. Earlier discharge after spinal anesthesia using the socalled mini-dose techniques will clearly improve its cost- 
TABLE IV Criteria for fast-tracking outpatients after ambulatory surgery. A minimum score of 12 , with no score $<1$ in any individual category, would be required for a patient to be fast-tracked after general anesthesia ${ }^{47}$

\begin{tabular}{lr}
\hline I. Level of consciousness & Score \\
awake and oriented & 2 \\
arousable with minimal stimulation & 1 \\
$\quad$ responsive only to tactile stimulation & 0 \\
II. Physical activity & 2 \\
able to move all extremities on command & 1 \\
some weakness in movement of extremities & 0 \\
unable to voluntarily move extremities & \\
III.Hemodynamic stability & 2 \\
$\quad$ blood pressure < 15\% of baseline MAP value & 1 \\
blood pressure between 15-30\% of baseline MAP value & 1 \\
blood pressure > 30\% below baseline MAP value & 0 \\
IV. Respiratory stability & 2 \\
able to breathe deeply & 1 \\
tachypnea with good cough & 0 \\
dyspneic with weak cough & \\
V. Oxygen saturation status & 2 \\
maintains value > $90 \%$ on room air & 1 \\
requires supplemental oxygen (nasal prongs) & 0 \\
saturation less than 90\% with supplemental oxygen & \\
VI. Postoperative pain assessment & \\
none or mild discomfort & 2 \\
moderate-to-severe pain controlled with iv analgesics & 1 \\
persistent severe pain & 0 \\
VII. Postoperative emetic symptoms & \\
none or mild nausea with no active vomiting & 2 \\
transient vomiting or retching & 1 \\
persistent moderate-severe nausea and vomiting & 0 \\
\hline
\end{tabular}

MAC $=$ monitored anesthesia care.

effectiveness in the ambulatory setting. Unfortunately, side effects such as pruritis and nausea are increased even when small doses of fentanyl (or sufentanil) are administered into the subarachnoid space. ${ }^{15}$

Even though central neuroaxial blocks can be made more cost-effective by using smaller doses of shortacting local anesthetics combined with potent opioid analgesics, use of MAC techniques for superficial (non-cavitary) ambulatory surgery procedures will result in the shortest times to home readiness, lowest pain scores at discharge, and smallest incremental costs when compared to both spinal and general anesthesia. ${ }^{10,11}$ Therefore, in situations where fast-tracking is permitted, the use of MAC techniques would appear to offer significant advantages over both central neuroaxis blocks (i.e., spinal/epidural) and general anesthetic techniques.

The availability of more rapid and shorter-acting $i v$ and inhaled anesthetics, analgesics and adjunctive drugs, as well as improved cerebral monitoring capabilities, has facilitated the recovery process after gen- eral anesthesia. For example, studies involving the use of "light" general anesthetic techniques with a laryngeal mask airway device and local analgesia have demonstrated that outpatients undergoing superficial surgical procedures (e.g., hernia repair, breast surgery) are able to ambulate within $30 \mathrm{~min}$ and can be discharged home in less than $60 \mathrm{~min}$ after completion of their operation. ${ }^{36-38}$ When tracheal intubation is required [e.g., laparoscopic procedures, risk factors for aspiration (e.g., diabetics, morbidly obese, esophageal dysfunction)], use of minimal, effective doses of newer short-acting opioid analgesics (e.g., remifentanil) and sympatholytic (e.g., esmolol) drugs can facilitate the early recovery process and allow patients to achieve earlier discharge times after ambulatory surgery. ${ }^{39-42}$ The use of the more costly drugs can be economically justified if improvements in recovery and work patterns can be demonstrated. ${ }^{43}$ However, anesthetic practices have advanced to the point where cost savings from variations in drug use are only apparent when system-wide improvements are made in the efficacy of resource utilization (including personnel, space, time, consumables and capital investments). ${ }^{44}$

\section{Fast-tracking concepts}

Ambulatory anesthesia is administered with the dual goals of rapidly and safely establishing satisfactory conditions for the performance of therapeutic or diagnostic procedures while ensuring a rapid, predictable recovery with minimal postoperative sequelae. If the careful titration of short-acting drugs permits a safe transfer of patients directly from the OR suite to the less labor-intensive recovery area where the patient can be discharged home within one hour after surgery, significant cost savings to the institution can be achieved. ${ }^{44}$ Bypassing the Phase I recovery (i.e., PACU) has been termed "fast-tracking" after ambulatory surgery. ${ }^{45}$ In addition, fast-tracking can also be accomplished directly from the PACU by creating a specialized area where recovery procedures are organized along the lines of a step-down unit. ${ }^{46}$ The criteria used to determine fast-track eligibility (Table IV) ${ }^{47}$ has been made even more stringent than the standard PACU discharge criteria in order to reduce the need for interventions in areas with less nursing personnel. The use of anesthetic techniques associated with a more rapid recovery will result in fewer patients remaining deeply sedated in the early postoperative period, ${ }^{30,48}$ decrease the risk for airway obstruction and cardiorespiratory instability, and reduce the number of nursing interventions. ${ }^{49}$ By reducing the need for "intensive" nursing care in the early postoperative period using anesthetic techniques associated with a 
faster emergence from anesthesia, a well-organized fast tracking program can permit an institution to use fewer nurses in the recovery areas and leads to significant cost savings. ${ }^{50}$ The fast-track concept is gaining wider acceptance throughout the world. ${ }^{51}$ Even elderly outpatients can be fast-tracked after general anesthesia if short-acting drugs are utilized. ${ }^{49}$

Improved titration of anesthetic drugs using electroencephalogram-based cerebral monitors (e.g., bispectral index [BIS], physical state index [PSI], auditory-evoked potential [AEP], and entropy) can lead to a faster emergence from anesthesia ${ }^{52,53}$ and can be useful in predicting fast-track eligibility. ${ }^{54}$ Although the early studies involving propofol ${ }^{52}$ and the newer volatile anesthetics sevoflurane and desflurane, ${ }^{53}$ suggested that the anesthetic-sparing effect could facilitate a faster emergence from anesthesia, these studies failed to demonstrate a decrease in the times to discharge home because standard recovery practices were used. However, if outpatients are allowed to recover via a fast-track pathway, use of cerebral monitoring can actually reduce discharge times. ${ }^{55}$

While the availability of more rapid and shorter-acting anesthetic drugs (e.g., propofol, sevoflurane, desflurane, remifentanil) has clearly facilitated the early recovery process after general anesthesia, the preemptive use of non-opioid analgesics (e.g., local anesthetics, ketamine, nonsteroidal anti-inflammatory drugs, COX-2 inhibitors, acetaminophen $)^{56}$ and antiemetics (e.g., droperidol, metoclopramide, 5- $\mathrm{HT}_{3}$ antagonists, dexamethasone), ${ }^{57}$ will reduce postoperative side effects and accelerate both the immediate and late recovery phases after ambulatory surgery.

\section{Multimodal approaches to preventing postoperative complications}

As more complex procedures are performed utilizing minimally-invasive surgical approaches (e.g., laparoscopic adrenalectomy, arthroscopic knee and shoulder reconstructions), the ability to effectively control postoperative side effects may make the difference between performing a given procedure on an inpatient or ambulatory basis. For routine antiemetic prophylaxis, the most cost-effective combination consists of low-dose droperidol $(0.5-1 \mathrm{mg})$ and dexamethasone $(4-8 \mathrm{mg}) .^{58}$ Interestingly, dexamethasone appears to facilitate an earlier discharge independent of its effects on PONV. ${ }^{59,60}$ Outpatients at high risk of PONV will benefit from the addition of a $5-\mathrm{HT}_{3}$ antagonist (e.g., ondansetron, dolasetron, granisetron $)^{61,62}$ or an acustimulation device (e.g., SeaBand $®$, ReliefBand $®) .{ }^{63,64}$ Droperidol remains the most cost-efffective antiemetic assuming side effects can be avoided. ${ }^{65,66}$ Although controversy exists regarding its potential for cardiac arrhythmias, droperidol has remained a safe and effective antiemetic for over 30 years. ${ }^{67}$ An aggressive multimodal approach to minimize PONV can improve the recovery process and enhance patient satisfaction. ${ }^{68}$ In addition to utilizing combination antiemetic therapy, simply ensuring adequate hydration will minimize nausea and other side effects (e.g., dizziness, drowsiness, thirst) during the postoperative period. ${ }^{69}$

A multimodal (or "balanced") approach to providing postoperative analgesia is also essential in the ambulatory setting. ${ }^{70-72}$ Not surprisingly, pain has been found to be a major factor complicating recovery and delaying discharge after ambulatory surgery. ${ }^{73}$ The addition of low-dose ketamine $\left(75-150 \mu \mathrm{g} \cdot \mathrm{kg}^{-1}\right)$ to a multimodal analgesic regimen improved postoperative analgesia and functional outcome after painful orthopedic surgery procedures. ${ }^{74,75}$ Following outpatient surgery, pain must be controllable with oral analgesics (e.g., acetaminophen, ibuprofen, acetaminophen with codeine) before patients are discharged from the facility. Although the potent rapid-acting opioid analgesics (e.g., fentanyl, sufentanil) are commonly used to treat moderate-to-severe pain in the early recovery period, these compounds increase the incidence of PONV and may contribute to a delayed discharge after ambulatory surgery. ${ }^{56,73}$ As a result of the concerns regarding opioid-related side effects, there has been an increased interest in the use of potent non-steroidal anti-inflammatory agents (e.g., diclofenac, ketorolac), which can effectively reduce the requirements for opioid-containing oral analgesics after ambulatory surgery, and can lead to an earlier discharge home. ${ }^{76}$ Other less expensive oral non-steroidal analgesics (e.g., ibuprofen, naproxen $)^{77,78}$ may be acceptable alternatives to fentanyl and the parenteral non-selective non-steroidal anti-inflammatory drugs if administered in a preemptive fashion. Recently, premedication with the COX-2 inhibitors (e.g., celecoxib, rofecoxib, valdecoxib, parecoxib) has become more popular because they are devoid of potential adverse effects on platelet function. ${ }^{79}$ For routine clinical use, oral premedication with rofecoxib (50 $\mathrm{mg}$ ), celecoxib (400 $\mathrm{mg}$ ) or valdecoxib $(40 \mathrm{mg}$ ) is a simple and cost-effective approach to improving pain control and decreased discharge times after ambulatory surgery ${ }^{80-84}$ The injectable COX-2 inhibitor, parecox$\mathrm{ib}$, may prove useful in the future. ${ }^{85,86}$ Finally, acetaminophen is a very cost-effective alternative to the COX-2 inhibitors if it can be given in a high enough dose $(40-60 \mathrm{mg} \cdot \mathrm{kg}$ po or $\mathrm{pr}$ ) prior to the end of surgery. ${ }^{87,88}$

One of the keys to facilitating the recovery process is the routine use of local anesthetics as part of a multi- 
modal regimen. ${ }^{56}$ Use of local anesthetic techniques for intraoperative analgesia during $\mathrm{MAC}$, as well as adjuncts to general (and spinal) anesthesia, can provide excellent analgesia during the early postoperative recovery and postdischarge periods. ${ }^{4,18,19}$ Even simple wound infiltration and instillation techniques have been shown to improve postoperative analgesia following a variety of lower abdominal, peripheral extremity and even laparoscopic procedures. A wide variety of peripheral extremity blocks have also been utilized to minimize postoperative pain..$^{89,90}$ More recently, use of continuous local anesthetic delivery systems (e.g., I-Flow) have been found to improve pain control after major ambulatory orthopedic surgery by extending periopheral nerve blocks. ${ }^{91-93}$ Patient-controlled local anesthetic delivery has also been described for improving pain relief after discharge home. ${ }^{94}$ Following laparoscopic procedures, abdominal pain can also be minimized by the use of a local anesthesia at the portals and topically applied at the surgical site. ${ }^{95,96}$ Shoulder pain is also common following laparoscopic surgery, and this has been reported to be reduced with subdiaphragmatic instillation of local anesthetic solutions. ${ }^{95}$ Following arthroscopic knee surgery, instillation of $30 \mathrm{~mL}$ of bupivacaine $0.5 \%$ into the joint space reduces postoperative opiate requirements and permits earlier ambulation and discharge. ${ }^{96}$ The addition of morphine (1-2 mg), ketorolac (15-30 mg), clonidine (0.1-0.2 $\mathrm{mg}$ ) and/or triamcinolone $(10-20 \mathrm{mg})$ to the intraarticular local anesthetic solution can further reduce pain after arthroscopic surgery. ${ }^{97-99}$ Electroanalgesia can also be used as part of a multimodal treatment regimen. ${ }^{100}$ Future growth in the complexity of surgical procedures being performed on an ambulatory basis will require further improvements in our ability to provide effective postoperative pain relief outside the surgical facility (e.g., sc opioid patient-contolled analgesia, patient-controlled local anesthesia with a disposable infusion system, transcutaneous analgesic delivery systems).

\section{Summary}

Ambulatory anesthesia has become recognized as an anesthetic subspecialty, with the institution of formal postgraduate training programs. Expansion of the specialty of ambulatory anesthesia and surgery is likely to continue with the growth in minimally-invasive (socalled keyhole) surgical procedures. The rate of expansion of ambulatory anesthesia will probably vary depending upon local needs, the level of ancillary home healthcare services, and economic considerations. ${ }^{101}$ Many recently developed drugs have pharmacological profiles which are ideally suited for use in the ambulatory setting. Use of newer anesthetic and anal- gesic drugs (e.g., desflurane, sevoflurane, remifentanil, parecoxib) and brain monitoring systems (e.g., BIS, PSA, and AEP devices) should facilitate fast-tracking in the ambulatory setting, leading to an early discharge after most surgery procedures without compromising patient safety. To maintain the high level of patient safety, mandatory accreditation and credentialing procedures are needed for both hospital-based and free-standing ambulatory surgery facilities. ${ }^{102}$

Given the changing pattern of health care reimbursement, it is incumbent upon all practitioners to carefully examine the impact of new drugs and devices on the quality of ambulatory anesthesia care they are providing to the patient. Future studies on new drugs and techniques for ambulatory anesthesia need to focus not only on subjective improvements for the patient during the immediate perioperative period, but also on the overall cost-effectiveness of the care being provided. ${ }^{28}$ These studies must compare the increased cost of newer treatments with the potential financial savings resulting from earlier discharge home, reduced consumption of supplemental drugs, improvements in patient satisfaction, and perhaps most importantly, resumption of normal activity. The future challenge that all practitioners must face is to provide high-quality ambulatory anesthesia care for more complex surgical procedures performed in a wide variety of venues. Finally, the need to administer the most cost-effective anesthetic technique for a given ambulatory surgery procedure will likely assume increased importance in the future.

\section{References}

1 White PF. Ambulatory Anesthesia and Surgery. London: W.B. Saunders Publishers; 1997: 1-918.

2 Patel NJ, Flashburg MH, Paskin S, Grossman R. A regional anesthetic technique compared to general anesthesia for outpatient knee arthroscopy. Anesth Analg 1986; 65: 185-7.

3 Young DV. Comparison of local, spinal, and general anesthesia for inguinal herniorrhaphy. Am J Surg 1987; 153: 560-3.

4 Tverskoy $M$, Cozacov $C$, Ayache $M$, et al. Postoperative pain after inguinal herniorrhaphy with different types of anesthesia. Anesth Analg 1990; 70: 29-35.

5 Jankowski CJ, Hebl JR, Stuart MJ, et al. A comparison of psoas compartment block and spinal and general anesthesia for outpatient knee arthroscopy. Anesth Analg 2003; 97: 1003-9.

6 Fleischer M, Marini CP, Statman R, et al. Local anesthesia is superior to spinal anesthesia for anorectal surgical procedures. Am Surg 1994; 60: 812-5.

7 Chilvers CR, Goodwin A, Vaghadia H, Mitchell GW. 
Selective spinal anesthesia for outpatient laparoscopy: pharmacoeconomic comparison vs general anesthesia. Can J Anesth 2001; 48: 279-83.

8 Williams CR, Thomas NP. A prospective trial of local versus general anaesthesia for arthroscopic surgery of the knee. Ann R Coll Surg Engl 1997; 79: 345-8.

9 Coloma M, Chin JW, White PF, et al. Fast-tracking after immersion lithotripsy: general anesthesia versus monitored anesthesia care. Anesth Analg 2000 91: 92-6.

10 Li S, Coloma M, White PF, et al. Comparison of the costs and recovery profiles of three anesthetic techniques for ambulatory anorectal surgery. Anesthesiology 2000; 93: 1225-30.

11 Song D, Greilich NB, White PF, et al. Recovery profiles and costs of anesthesia for outpatient unilateral inguinal herniorrhaphy. Anesth Analg 2000; 91: 876-81.

12 Mulroy MF, Larkin KL, Hodgson PS, et al. A comparison of spinal, epidural, and general anesthesia for outpatient knee arthroscopy. Anesth Analg 2000; 91: 860-4.

13 Ben-David B, Maryanovsky M, Gurevitch A, et al. A comparison of minidose lidocaine-fentanyl and conventional-dose lidocaine spinal anesthesia. Anesth Analg 2000; 91: 865-70.

14 Williams BA, Kentor ML, Williams JP, et al. Process analysis in outpatient knee surgery: effect of regional and general anesthesia on anesthesia-controlled time. Anesthesiology 2000; 93: 529-38.

15 Ben-David B, DeMeo PJ, Lucyk C, Solosko D. A comparison of minidose lidocaine-fentanyl spinal anesthesia and local anesthesia/propofol infusion for outpatient knee arthroscopy. Anesth Analg 2001 93: 319-25.

16 Keblet H, White PF. Optimizing anesthesia for inguinal herniorrhaphy - general regional or local anesthesia? (Editorial). Anesth Analg 2001; 93: 1367-9.

17 White PF, Watcha MF. Postoperative nausea and vomiting: prophylaxis versus treatment (Editorial). Anesth Analg 1999; 89: 1337-9.

18 Harrison CA, Morris S, Harvey JS. Effect of ilioinguinal and iliohypogastric nerve block and wound infiltration with $0.5 \%$ bupivacaine on postoperative pain after hernia repair. Br J Anaesth 1994; 72: 691-3.

19 Ding $\Upsilon$, White PF. Post-herniorrhaphy pain in outpatients after pre-incision ilioinguinal-hypogastric nerve block during monitored anaesthesia care. Can J Anaesth 1995; 42: 12-5.

20 Tong D, Chung F, Wong D. Predictive factors in global and anesthesia satisfaction in ambulatory surgical patients. Anesthesiology 1997; 87: 856-64.
21 Marshall SI, Chung F. Discharge criteria and complications after ambulatory surgery. Anesth Analg 1999; 88: 508-17.

22 Pollock JE, Neal JM, Stephenson CA, Wiley CE.

Prospective study of the incidence of transient radicular irritation in patients undergoing spinal anesthesia. Anesthesiology 1996; 84: 1361-7.

23 Halpern S, Preston R. Postdural puncture headache and spinal needle design. Metaanalyses. Anesthesiology 1994; 81: 1376-83.

24 Vloka JD, Hadzic A, Mulcare R, et al. Femoral and genitofemoral nerve blocks versus spinal anesthesia for outpatients undergoing long saphenous vein stripping surgery. Anesth Analg 1997; 84: 74-52.

25 Price $R$. Transient femoral nerve palsy complicating preoperative ilioinguinal nerve blockade for inguinal herniorrhaphy. Br J Surg 1995; 82: 137-8.

26 Rosario DJ, Skinner PP, Raftery AT. Transient femoral nerve palsy complicating preoperative ilioinguinal nerve blockade for inguinal herniorrhaphy. $\mathrm{Br}$ J Surg 1994; 81: 897.

27 Dexter F, Tinker JH. Analysis of strategies to decrease postanesthesia care unit costs. Anesthesiology 1995; 82: 94-101.

28 Watcha MF, White PF. Economics of anesthetic practice. Anesthesiology 1997; 86: 1170-96.

29 Coloma M, Chin JW, White PF, Armbruster SC. The use of esmolol as an alternative to remifentanil during desflurane anesthesia for fast-track outpatient gynecologic laparoscopy surgery. Anesth Analg 2001; 92: 352-7.

30 Coloma M, Zhou T, White PF, Forestner JE. Fast-tracking after outpatient laparoscopy: reasons for failure after propofol, sevoflurane and desflurane anesthesia. Anesth Analg 2001; 93: 112-5.

31 Sa Rego MM, Watcha MF, White PF. The changing role of monitored anesthesia care in the ambulatory setting. Anesth Analg 1997; 85: 1020-36.

32 Calleson, Bech T, Keblet H. One-thousand consecutive inguinal hernia repairs under unmonitored local anesthesia. Anesth Analg 2001; 93: 1373-6.

33 Jacobson E, Forssblad M, Rosenberg J, et al. Can local anesthesia be recommended for routine use in elective knee arthroscopy? A comparison between local, spinal, and general anesthesia. Arthroscopy 2000; 16: 183-90.

34 Fairclough JA, Graham GP, Pemberton D. Local or general anaesthetic in day-case arthroscopy? Ann $\mathrm{R}$ Coll Surg Engl 1990; 72: 104-7.

35 Trieshmann $H W$. Knee arthroscopy: a cost analysis of general and local anesthesia. Arthroscopy 1996; 12: 60-3.

36 Tang J, Chen L, White PF, et al. Use of propofol for 
office-based anesthesia: effect of nitrous oxide on recovery profile. J Clin Anesth 1999; 11: 226-30.

37 Tang J, Chen L, White PF, et al. Recovery profile, costs, and patient satisfaction with propofol and sevoflurane for fast-track office-based anesthesia. Anesthesiology 1999; 91: 253-61.

38 Tang J, White PF, Wender RH, et al. Fast-track officebased anesthesia: a comparison of propofol versus desflurane with antiemetic prophylaxis in spontaneously breathing patients. Anesth Analg 2001; 92: 95-9.

39 Song D, White PF. Remifentanil as an adjuvant during desflurane anesthesia facilitates early recovery after ambulatory surgery. J Clin Anesth 1999; 11: 364-7.

40 Song D, Whitten CW, White PF. Remifentanil infusion facilitates early recovery for obese outpatients undergoing laparoscopic cholecystectomy. Anesth Analg 2000; 90: 1111-3.

41 Coloma M, Chin JW, White PF, Armbruster SC. The use of esmolol as an alternative to remifentanil during desflurane anesthesia for fast-track outpatient gynecologic laparoscopic surgery. Anesth Analg 2001; 92: 352-7.

42 White PF, Wang B, Tang J, et al. Effect of intraoperative use of esmolol and nicardipine on recovery after ambulatory surgery. Anesth Analg 2003; 97: 1633-8.

43 Eger EI, White PF, Bogetz MS. Clinical and economic factors important to anesthetic choice for day-case surgery. Pharmacoeconomics 2000; 17: 245-62.

44 Dexter F, Marcario A, Manberg PJ, Lubarsky DA. Computer simulation to determine how rapid anesthetic recovery protocols to decrease the time for emergence or increase the phase I postoperative care unit bypass rate affect staffing of an ambulatory surgery center. Anesth Analg 1999; 88: 1053-63.

45 Watkins AC, White PF. Fast-tracking after ambulatory surgery. J Perianesth Nurs 2001; 16: 379-87.

46 White PF, Rawal S, Nguyen J, Watkins A. PACU fasttracking: an alternative to "bypassing" the PACU for facilitating the recovery process after ambulatory surgery. J Perianesth Nurs 2003; 18: 247-53.

47 White PF, Song D. New criteria for fast-tracking after outpatient anesthesia: a comparison with the modified Aldrete's scoring system. Anesth Analg 1999; 88: 1069-72.

48 Song D, Joshi GP, White PF. Fast-track eligibility after ambulatory anesthesia: a comparison of desflurane, sevoflurane, and propofol. Anesth Analg 1998; 86: 267-73.

49 Fredman B, Sheffer O, Zohar E, et al. Fast-track eligibility of geriatric patients undergoing short urologic surgery procedures. Anesth Analg 2002; 94: 560-4.

50 Apfelbaum JL, Walawander CA, Grasela TH, et al.
Eliminating intensive postoperative care in same-day surgery patients using short-acting anesthetics. Anesthesiology 2002; 97: 66-74.

51 Duncan PG, Shandro J, Bachand R, Ainsworth L. A pilot study of recovery room bypass ("fast-track protocol") in a community hospital. Can J Anesth 2001; 48: 630-6.

52 Gan TJ, Glass PS, Windsor A, et al. Bispectral index monitoring allows faster emergence and improved recovery from propofol, alfentanil, and nitrous oxide anesthesia. Anesthesiology 1997; 87: 808-15.

53 Song D, Joshi GP, White PF. Titration of volatile anesthetics using bispectral index facilitates recovery after ambulatory anesthesia. Anesthesiology 1997; 87: 842-8.

54 Song D, Van Vlymen J, White PF. Is the bispectral index useful in predicting fast-track eligibility after ambulatory anesthesia with propofol and desflurane? Anesth Analg 1998; 87: 1245-8.

55 White PF, Ma H, Tang J, et al. Does the use of electroencephalographic bispectral index or auditory evoked potential index monitoring facilitate recovery after desflurane anesthesia in the ambulatory setting? Anesthesiology 2004; 100: 811-7.

56 White PF. The role of non-opioid analgesic techniques in the management of pain after ambulatory surgery. Anesth Analg 2002; 94: 577-85.

57 White PF, Watcha MF. Postoperative nausea and vomiting: prophylaxis versus treatment. Anesth Analg 1999; 89: 1337-9.

58 Tang J, Chen X, White PF, et al. Antiemetic prophylaxis for office-based surgery: are the 5-HT3 receptor antagonists beneficial? Anesthesiology 2003; 98: 293-8.

59 Coloma M, Duffy LL, White PF, et al. Dexamethasone facilitates discharge after outpatient anorectal surgery. Anesth Analg 2001; 92: 85-8.

60 Coloma M, White PF, Markowitz SD, et al. Dexamethasone in combination with dolasetron for prophylaxis in the ambulatory setting: effect on outcome after laparoscopic cholecystectomy. Anesthesiology 2002; 96; 1346-50.

61 Tang J, Wang B, White PF, et al. Effect of timing of ondansetron administration on its efficacy, cost-effectiveness, and cost-benefit as a prophylactic antiemetic in the ambulatory setting. Anesth Analg 1998; 86: 274-82.

62 Zarate E, Watcha MF, White PF, et al. A comparison of the costs and efficacy of ondansetron versus dolasetron for antiemetic prophylaxis. Anesth Analg 2000 90: 1352-8.

63 Zarate E, Mingus M, White PF, et al. The use of transcutaneous acupoint electrical stimulation for prevent- 
ing nausea and vomiting after laparoscopic surgery. Anesth Analg 2001; 92: 629-35.

64 White PF, Issioui T, Hu J, et al. Comparative efficacy of acustimulation (ReliefBand $\AA$ ) versus ondansetron (Zofran () in combination with droperidol for preventing nausea and vomiting. Anesthesiology 2002: 97: 1075-81.

65 Tang J, Watcha MF, White PF. A comparison of costs and efficacy of ondansetron and droperidol as prophylactic antiemetic therapy for outpatient procedures. Anesth Analg 1996; 83: 304-13.

66 Hill RP, Lubarsky DA, Phillips-Bute B, et al. Costeffectiveness of prophylactic antiemetic therapy with ondansetron, droperidol, or placebo. Anesthesiology 2000; 92: 958-67.

67 White PF. Droperidol: a cost-effective antiemetic for over thirty years. Anesth Analg 2002; 95: 789-90.

68 Scuderi PE, James RL, Harris L, Mimms GR. Multimodal antiemetic management prevents early postoperative vomiting after outpatient laparoscopy. Anesth Analg 2000; 91: 1408-14.

69 Yogendran S, Asokumar B, Cheng D, Chung F. A prospective, randomized double-blind study of the effect of intravenous fluid therapy on adverse outcomes after outpatient surgery. Anesth Analg 1995; 80: 682-6.

70 Keblet $H$. Postoperative pain relief - What is the issue? (Editorial). Br J Anaesth 1994; 72: 387-40.

71 Eriksson H, Tenhunen A, Korttila K. Balanced analgesia improves recovery and outcome after outpatient tubal ligation. Acta Anaesthesiol Scand 1996; 40: 151-5.

72 Michaloliakou C, Chung F, Sharma S. Preoperative multimodal analgesia facilitates recovery after ambulatory laparoscopic cholecystectomy. Anesth Analg 1996; 82: 44-51.

73 Pavlin DJ, Chen C, Penaloza DA, et al. Pain as a factor complicating recovery and discharge after ambulatory surgery. Anesth Analg 2002; 95: 627-34.

74 Menigaux C, Guignard B, Fletcher D, et al. Intraoperative small-dose ketamine enhances analgesia after outpatient knee arthroscopy. Anesth Analg 2001; 93: 606-12.

75 Menigaux C, Fletcher D, Dupont X, et al. The benefits of intraoperative small-dose ketamine on postoperative pain after anterior curciate ligament repair. Anesth Analg 2000; 90: 129-35.

76 Coloma M, White PF, Huber PJ, et al. Effect of ketorolac on recovery after anorectal surgery: intravenous vs local administration. Anesth Analg 2000; 90: 1107-10.

77 Rosenblum M, Weller RS, Conrad PL, et al. Ibuprofen provides longer lasting analgesia than fentanyl after laparoscopic surgery. Anesth Analg 1991; 73: 255-9.

78 Raeder JC, Steine S, Vatsgar TT. Oral ibuprofen versus paracetamol plus codeine for analgesia after ambulatory surgery. Anesth Analg 2001; 92: 1470-2.

79 Souter AJ, Fredman B, White PF. Controversies in the perioperative use of nonsteroidal anti-inflammatory drugs. Anesth Analg 1994; 79: 1187-90.

80 Issioui T, Klein KW, White PF, et al. The efficacy of premedication with celecoxib and acetaminophen in preventing pain after otolaryngologic surgery. Anesth Analg 2002; 94: 1188-93.

81 Issioni T, Klein KW, White PF, et al. Cost-efficacy of rofecoxib versus acetaminophen for preventing pain after ambulatory surgery. Anesthesiology 2002; 97: 931-7.

82 Recart A, Issioui T, White PF, et al. The efficacy of celecoxib premedication on postoperative pain and recovery times after ambulatory surgery: a dose-ranging study. Anesth Analg 2003; 96: 1631-5.

83 Watcha MF, Issioni T, Klein KW, White PF. Costs and effectiveness of rofecoxib, celecoxib and acetaminophen for preventing pain after ambulatory otolaryngologic surgery. Anesth Analg 2003: 96: 987-94.

84 Ma H, Tang J, White PF, et al. Perioperative rofecoxib improves early recovery after outpatient herniorrhaphy. Anesth Analg 2004; 98: 970-5.

85 Tang J, Li S, White PF, et al. Effect of parecoxib, a novel intravenous cyclooxygenase- 2 inhibitor, on the postoperative opioid requirement and quality of pain control. Anesthesiology 2002; 96: 1305-9.

86 Desjardins PJ, Grossman EH, Kuss ME, et al. The injectable cyclooxygenase-2-specific inhibitor parecoxib sodium has analgesic efficacy when administered preoperatively. Anesth Analg 2001; 93: 721-7.

87 Rusy LM, Houck CS, Sullivan LJ, et al. A doubleblind evaluation of ketorolac versus acetaminophen in pediatric tonsillectomy: analgesia and bleeding. Anesth Analg 1995; 80: 226-9.

88 Korpela R, Konvenoja P, Meretoja $O A$. Morphinesparing effect of acetaminophen in pediatric day-care surgery. Anesthesiology 1999; 91: 442-7.

89 Ritchie ED, Tong D, Chung F, et al. Suprascapular nerve block for postoperative pain relief in arthroscopic shoulder surgery: a new modality? Anesth Analg 1997; 84: 1306-12.

90 Mulroy MF, Larkin KL, Batra MS, et al. Femoral nerve block with $0.25 \%$ or $0.5 \%$ bupivacaine improves postoperative analgesia following outpatient arthroscopic anterior cruciate ligament repair. Reg Anesth Pain Med 2001; 26: 24-9.

91 Grant SA, Nielsen KC, Greengrass RA, et al. Continuous periopheral nerve block for ambulatory 
surgery. Reg Anesth Pain Med 2001; 26: 209-14.

92 Illfeld BM, Morey TE, Wang RD, Enneking FK.

Continuous popliteal sciatic nerve for postoperative pain control at home. Anesthesiology 2002; 97 : 959-65.

93 White PF, Issioui T, Skrivanek GD, et al. Use of a continuous popliteal sciatic nerve block for the management of pain after major podiatric surgery: does it improve quality of recovery? Anesth Analg 2003; 97 : 1303-9.

94 Rawal N, Axelsson K, Hylander J, et al. Postoperative patient-controlled local anesthetic administration at home. Anesth Analg 1998; 86: 86-9.

95 Pasqualucci A, de Angelis V, Contardo R, et al. Preemptive analgesia: intraperitoneal local anesthetic in laparoscopic cholecystectomy. A randomized, double-blind, placebo-controlled study. Anesthesiology 1996; 85: 11-20.

96 Smith I, Shively RA, White PF. Effects of ketorolac and bupivacaine on recovery after outpatient arthroscopy. Anesth Analg 1992; 75: 208-12.

97 Stein C, Comisel K, Haimerl E, et al. Analgesic effect of intraarticular morphine after arthroscopic knee surgery. N Engl J Med 1991; 325: 1123-6.

98 Reuben S, Connelly NR. Postoperative analgesia for outpatient arthroscopic knee surgery with intraarticular clonidine. Anesth Analg 1999; 88: 729-33.

99 Wang JJ, Ho ST, Lee SC, et al. Intraarticular triamcinolone acetonide for pain control after arthroscopic knee surgery. Anesth Analg 1998; 87: 1113-6.

100 White PF, Li S, Chin JW. Electroanalgesia: its role in acute and chronic pain management. Anesth Analg 2001; 92: 505-13.

101 White PF. Ambulatory anesthesia advances into the new millennium. Anesth Analg 2000; 90: 1234-5.

102 Robrich RJ, White PF. Safety of outpatient surgery: is mandatory accreditation of outpatient surgery centers enough? Plastic Reconstr Surg 2001; 107:189-92. 